\title{
Model for Economic Comparison of Different Transportation Means in the Smart City
}

\author{
Aleksejs ZACEPINS, Armands KVIESIS, \\ Vitalijs KOMASILOVS, Nikolajs BUMANIS
}

Department of Computer Systems, Faculty of Information Technologies, Latvia University of Life Sciences and Technologies, Liela iela 2, Jelgava, LV-3001, Latvia

aleksejs.zacepins@llu.lv, armands.kviesis@llu.lv, vitalijs.komasilovs@llu.lv, nikolajs.bumanis@llu.lv

\begin{abstract}
Smart city is commonly described as "city for citizens" empowering citizen lives by implementing methods of smart economy, smart environment and smart mobility, all aimed to address such concerns as resource scarcity, air pollution, citizens health and traffic problems. These methods are usually implemented in invisible-to-citizen ways. To address previously mentioned concerns different requirements and guidelines are introduced. One of such concerns is citizens' commute, so corresponding requirements must be defined according to modern smart city goals, i.e., to be economically reasonable and beneficial, and should promote clean environment. The problems that arise are related to selection of proper transportation means for commute purposes. Aim of this paper is to propose a model for economic comparison of commute by use of different transportation means within the city taking into account person's wage.
\end{abstract}

Keywords: Smart city, smart transportation, economic model, transportation costs.

\section{Introduction}

Growing concern of urbanization creates several problems, like resource scarcity, air pollution, decrease of citizen health, traffic problems etc. (Marceau, 2008). Smart city is an emerging domain, but still there is no one common definition and explanation of this term and concept (Anthopoulos and Reddick, 2016; Cerutti et al., 2019). Smart city can be identified using several characteristics that include smart economy, smart people, smart mobility (transportation), smart environment and others (Mahizhnan, 1999). Smart city is also defined by the application of smart methods to build liveable and sustainable city (Chourabi et al., 2012). Smart city should also be a green city, which move towards green energy usage within the city as urban air pollution is one of the environmental risks in modern cities (Benevolo et al., 2013; Elsom, 2014). The popularity of bicycles and scooters, therefore, is growing as they are one of the green types of transportation. In case of short distances, transportation by bicycle, theoretically, can be the most preferable mean of transportation (Goodwill, 2015; Kitthamkesorn and Chen, 2017). Today there are many bike sharing (Fishman et al., 2013; Kaltenbrunner et al., 2010; Lu 
et al., 2018) or scooter sharing (Degele et al., 2018; Mayhew and Bergin, 2019) options in main European and world cities that promote sharing economy model (Mi and Coffman, 2019) for the citizens to increase the sharing vehicle usage popularity. Bike sharing can also provide health benefits (Woodcock et al., 2014) by avoidance of premature deaths (Mueller et al., 2018).

Many municipalities are changing their development strategies and define new mobility principles in cities, where mobility priority focuses on pedestrians, cyclists and public transport, but not on the private car drivers. Image below (see Fig.1) shows overall transportation concept within the smart city.

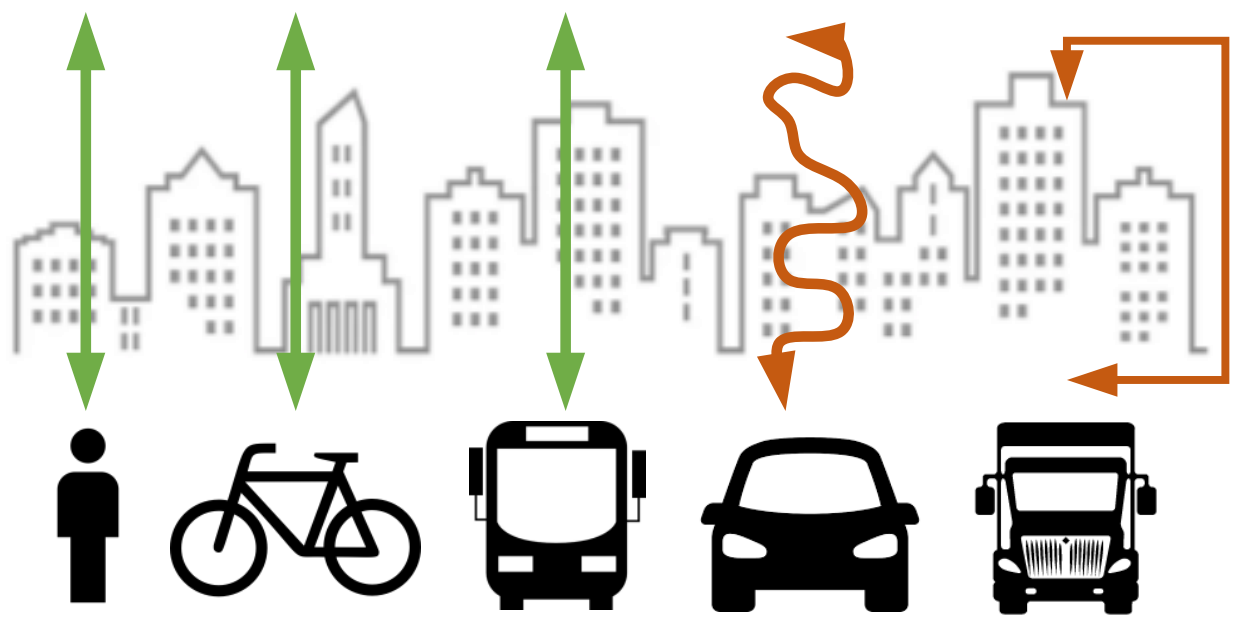

Fig. 1. Transportation concept in the smart city.

According to this concept, private cars have some restrictions and disadvantages (like paid entrance to the city centre or even to the city, paid parking, etc.), commercial and private trucks are not allowed to enter the city (except of goods delivery) at all. This concept is good for the city ecology, but from economic point of view could be discussable. Also, the choice of transport can affect the time in which residents can reach their destination within the city, e.g., work office or home. The are many publications available where cost of cars and bicycles are analysed, mainly for assessing the bicycle infrastructure projects (Gössling and Choi, 2015). Many authors tried to evaluate and understand costs and benefits connected with cycling and car driving (Becker et al., 2012; Hopkinson and Wardman, 1996; Krizec, 2007; Meschik, 2012; Ortúzar et al., 2000).

Time spent reaching the working place (also known as commuting time) is a decision making factor for almost all employees, excluding the ones working remotely. For some employees it could be a quick trip on a bike, in the car or on public transport, but for some people it could be a long journey with various types of transport. Some companies started to pay for commute time and include this time and expenses to an overall working time, some started to think about it. In case of mobile workers without constant office this is approved by a EU "European Court of Justice (ECJ) that travel time for 
mobile workers should be treated as working time, Nr. C-266/14“. One research shows why the commute should be counted as part of the working day (https://info.uwe.ac.uk/news/uwenews/news.aspx?id=3848), and number of such researches increases. Another research shows that commute can be one of the reasons to change the work and should be compensated or fully rewarded to the employees similar to healthcare insurance (https://www.tlnt.com/is-commuting-becoming-the-newhealthcare/).

Therefore, it can be assumed that in the future commute time will be included in the working time; moreover, it is required to evaluate which transportation mean is more economically beneficial for the employees to use. Aim of this paper is to propose a model for economic comparison of commute using different transportation means within the city taking into account person's wage.

\section{Materials and methods}

Any city situation around public transport and bike infrastructure introduce different limitations to the private car owners, but proposed economic model can be adjusted to local situation and requirements. Demonstration of the developed model uses the situation of the local city Jelgava in Latvia. Jelgava is the fourth largest city in Latvia, it is the historical centre of Zemgales region, distance from Latvia capital Riga is $42 \mathrm{~km}$, residents count is approx. 62 000. Jelgava is called a "students" city, because there are a lot of students from other cities, which makes a real number of people living in Jelgava much more (Zacepins et al., 2017).

Authors propose such model for calculation of travelling costs:

$$
C=I / v^{*} W+E_{t r}+E_{a d d}
$$

where

C - overall transportation (commuting) costs (EUR),

1 - distance to the destination $(\mathrm{km})$,

$\mathrm{v}$ - average speed of the transport unit $(\mathrm{km} / \mathrm{h})$,

$\mathrm{W}$ - person wage $(\mathrm{EUR} / \mathrm{h})$,

$\mathrm{E}_{\mathrm{tr}}-$ costs for transportation (EUR),

$\mathrm{E}_{\text {add }}$ - some possible additional costs (parking costs, additional time to get to

public transport, etc.).

One of the main variables used in a model is person wage per hour. In authors demonstration model person wage (W) is equal to $6.28 \mathrm{EUR} / \mathrm{h}$, as average salary in Latvia is 1004 EUR/month (by data of Central Statistical Bureau of Latvia, https://www.csb.gov.lv/en/). Authors compare four transportation options: walking, riding a bike, using public transportation and a private car.

Walking: First option is to walk to work. It is the slowest option for transportation, but does not require any investments. It is clear that there is a limit of a distance, which potentially could be covered by walking. Authors assume that the distance should not be 
more than $5 \mathrm{~km}$ or one hour of walking in one direction. Average walking speed for testing the model is assumed as $5 \mathrm{~km} / \mathrm{h}$.

Bicycle: Mean of transportation that is more often motivated by the government in many cities worldwide. Green nature of transport, do not have any restrictions within the city, except one limitation - availability of infrastructure for safe riding. However, even without the dedicated infrastructure it is possible to use the car infrastructure for bike riding. Average riding speed is assumed to be $15 \mathrm{~km} / \mathrm{h}$. Bicycle amortization costs (variable Etr), with the amount of approximately $0.04 \mathrm{EUR} / \mathrm{km}$, should also be taken into account. It is not very trivial task to precisely evaluate bike amortization costs, but authors divided bike cost of 500 EUR to five years. And then divided this to twenty working days, getting number 0.4 EUR per day. Then this number is divided to $10 \mathrm{~km}$ (that is average driving distance within the city per day).

Public transport: Depending on the city, public transport can include bus, tram, trolleybus, metro and city train. Ticket price differs from the ticket type (single trip, daily, weekly, monthly tickets, etc.). In the case of Jelgava city, only bus is available as a public transport, ticket price is $0.85 \mathrm{EUR} /$ ride (Etr) and average speed is calculated to be $20 \mathrm{~km} / \mathrm{h}$. The speed of the bus is calculated by randomly choosing several bus routes and based on information (route and time) provided by the local public transportation company (www.jap.lv) average bus speed is calculated and rounded. Table 1 provides example of calculations.

Table 1. Average bus speed calculations in Jelgava

\begin{tabular}{|c|c|c|c|}
\hline Bus number & Route distance $(\mathrm{km})$ & Time $(\min )$ & Speed $(\mathrm{km} / \mathrm{h})$ \\
\hline 4 & 5.8 & 17 & 20.47 \\
\hline 1 & 13 & 37 & 21.08 \\
\hline 22 & 5.4 & 16 & 20.25 \\
\hline 7 & 10.5 & 32 & 19.69 \\
\hline
\end{tabular}

In addition, time to get to the bus stop and then from the bus stop should be taken into consideration. Authors assumes it to be additional 5 minutes. So additional 0.52 EUR (variable Eadd) should be added to the calculation.

Private car: Most comfortable mean of transportation, as you are not dependent on public transport schedule and weather conditions. Average driving speed within the city is assumed to be $40 \mathrm{~km} / \mathrm{h}$. Average speed of the private car is evaluated based on authors experience and driving through the city. Car amortization costs, with the amount of approximately $0.3 \pm 0.15 \mathrm{EUR} / \mathrm{km}$ depending on the car, should be taken into account. There are online calculators available to evaluate the costs for own car (for example: https://financialmentor.com/calculator/car-cost-calculator). Additional limitation like payment for a parking (if employer is not providing it, or payment for the city centre entrance) should also be considered if applicable. In authors case these restrictions are not applicable. 


\section{Results}

Based on described methodology resulted model is demonstrated in figure below (see Fig.2):

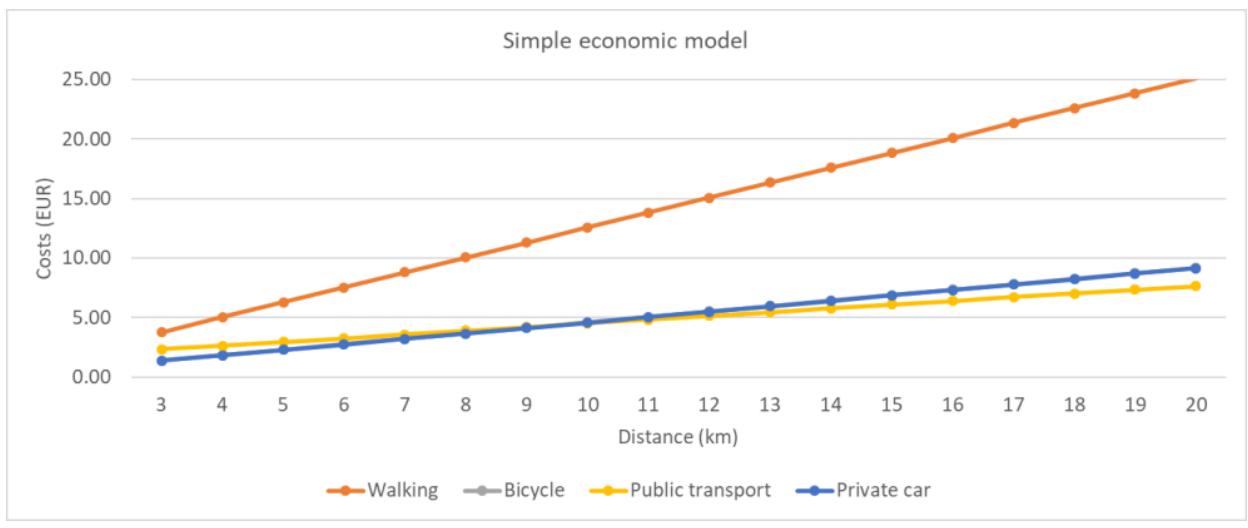

Fig. 2. Economic model for comparison of different transportation means.

Model demonstrates almost equal costs for using car, bicycle or public transportation. Car and bicycle slopes are almost identical, therefore, bicycle line is not visible in the figure. Each additional $\mathrm{km}$ when using a bike or a car costs 0.46 EUR and 0.31 EUR when using public transport. Taking person's wage into account, walking can not be considered at all, as the walking speed is slow compared to other transport and time spent by walking is much higher.

In fact, this model operates assuming that user already owns a vehicle (bike or car), but the next model takes into account purchase fact of the vehicle and includes this in the calculations.

\subsection{Advanced model (taking into account unit purchase price)}

It is hard to evaluate the purchase price of the vehicle as it depends on many factors, including the vehicle model, configuration, equipment etc. In example calculations authors assume leasing payment for the car equal to 200 EUR per month and leasing payment for the bicycle equal to 15 EUR per month. Taking into consideration that there are 20 working days per month, each day additionally costs 10 EUR for the car and 1.5 EUR for a bike, therefore one drive is equal to the half of this number ( 5 EUR and 0.75 EUR correspondingly). 


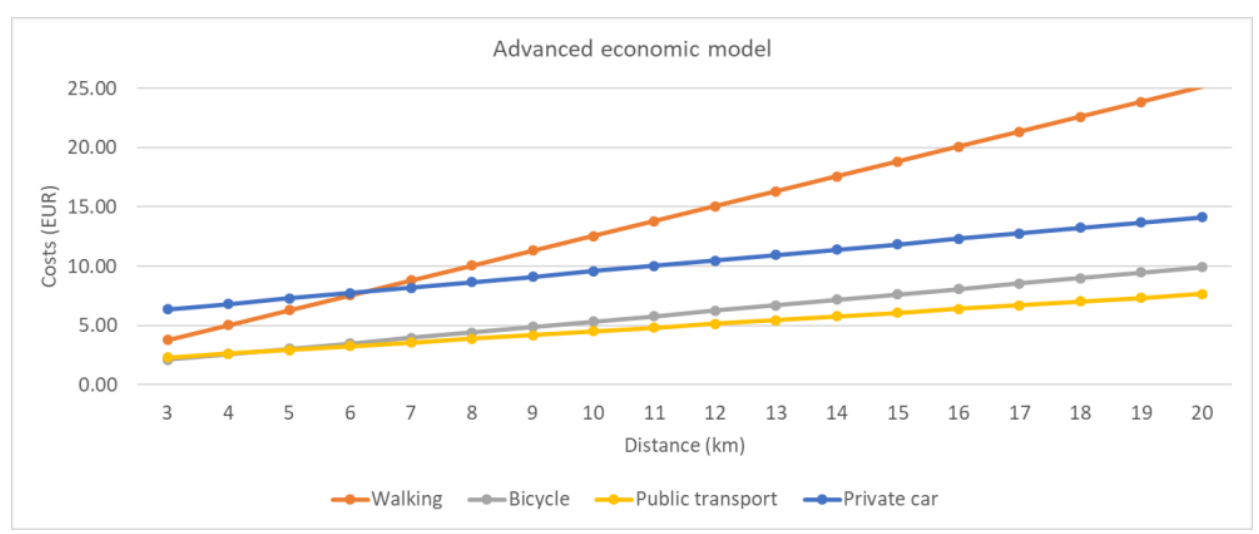

Fig. 3. Advanced economic model for comparison of different transportation means.

This model now shows, that taking into account possible leasing payment, costs for a car exceed the ones for a bike and public transport. In this model, the preferential option is to use public transport as it does not have any additional expenses. Also, walking can be more preferable comparing to a car if distance to the destination is less than $6 \mathrm{~km}$.

One more aspect to consider is using the vehicle (a car or a bike) not only for getting to work, but also for leisure, so some amount of the costs should be taken off and it is hard to evaluate this number.

Nowadays the concept of sharing services, like bike, scooter or car sharing, become more popular. Therefore, authors also decided to compare the option of owning a vehicle with usage of shared services (including taxi service).

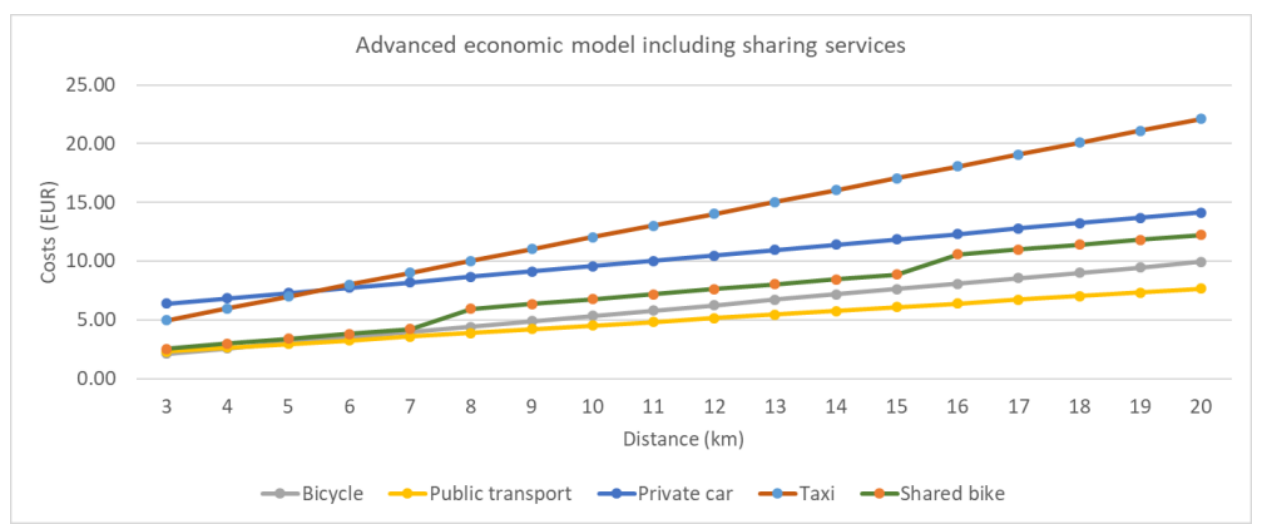

Fig. 4. Economic model with additional vehicle sharing services.

Costs for using a taxi in use case city Jelgava is as follows: 1.95 EUR to order a taxi, 0.64 EUR per $\mathrm{km}$ and 0.14 EUR per minute. Unfortunately, bike sharing is not available in the author's city Jelgava, so bike sharing in Riga by the company "SIXT" 
(https://www.sixtbicycle.lv/) is used as a reference for the costs calculations. Price for 30 min bike usage is 1.29 EUR.

Figure 4 shows that for the distances up to $6 \mathrm{~km}$ it is more beneficial to use a taxi than a private car, but the situation reverses after that point. Bike sharing is a good alternative to using a private car in case you do not own a bike, but still loses to owning a bike or using a public transport.

Previous calculations were made taking into account average salary of 6.28 EUR, but it is necessary to evaluate and compare how the commuting costs change according to different persons' wages.

Next chart (see Figure 5) shows comparison of costs for the distance of 5 and $10 \mathrm{~km}$ for main transportation means (bike, public transport and private car) according of persons' wage.

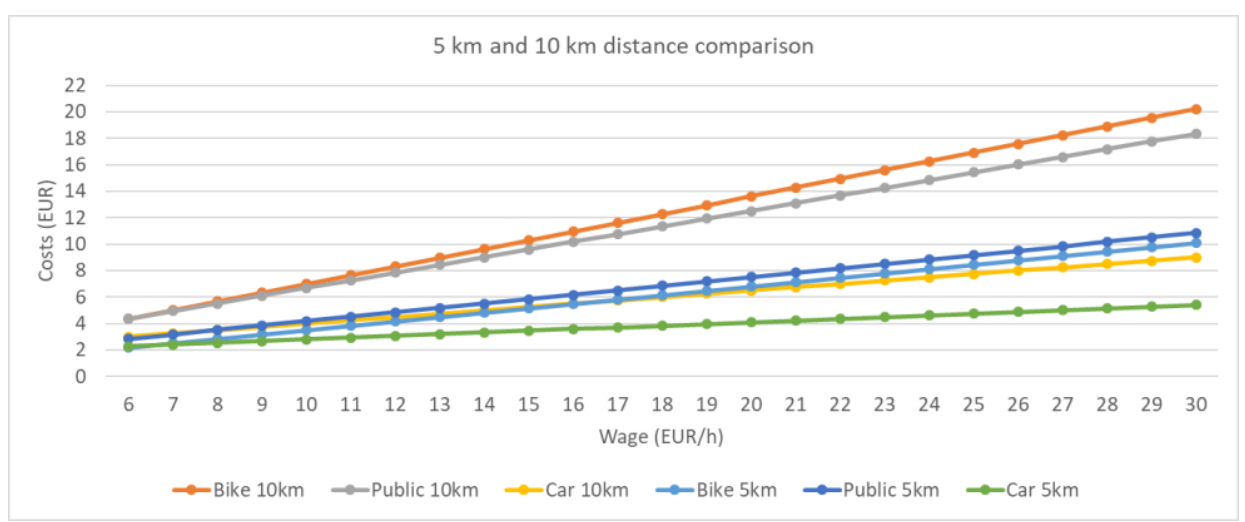

Fig. 5. Model for different wages for distances $5 \mathrm{~km}$ and $10 \mathrm{~km}$.

This model is based on a simple model, taking into account that user already has a bike or a car. In the case of $5 \mathrm{~km}$ distance when person wage reaches $8 \mathrm{EUR} / \mathrm{h}$ using a car becomes more beneficial, but a bike is more preferable than public transport. In longer distance $(10 \mathrm{~km}) \mathrm{car}$ is more preferable in any case, but public transport is more beneficial than a bike.

The models shows that it is more economically beneficial to use a private car, if there are no additional costs. When additional costs of approximately 10 EUR occurs for using a private car, then all transportation alternatives would have similar costs.

\subsection{Web tool for using a model}

To demonstrate the calculations a single page web application (see Fig. 6) was built using Angular 7 framework. User is allowed to change several parameters for different commute options. Total costs for each transportation mean and final result is updated on every input field change, so the user can easily compare costs among different transportation means. . The developed calculator is available for public use accessing the address: https://transport.science.itf.llu.lv/. 


\section{Transport choice calculations}

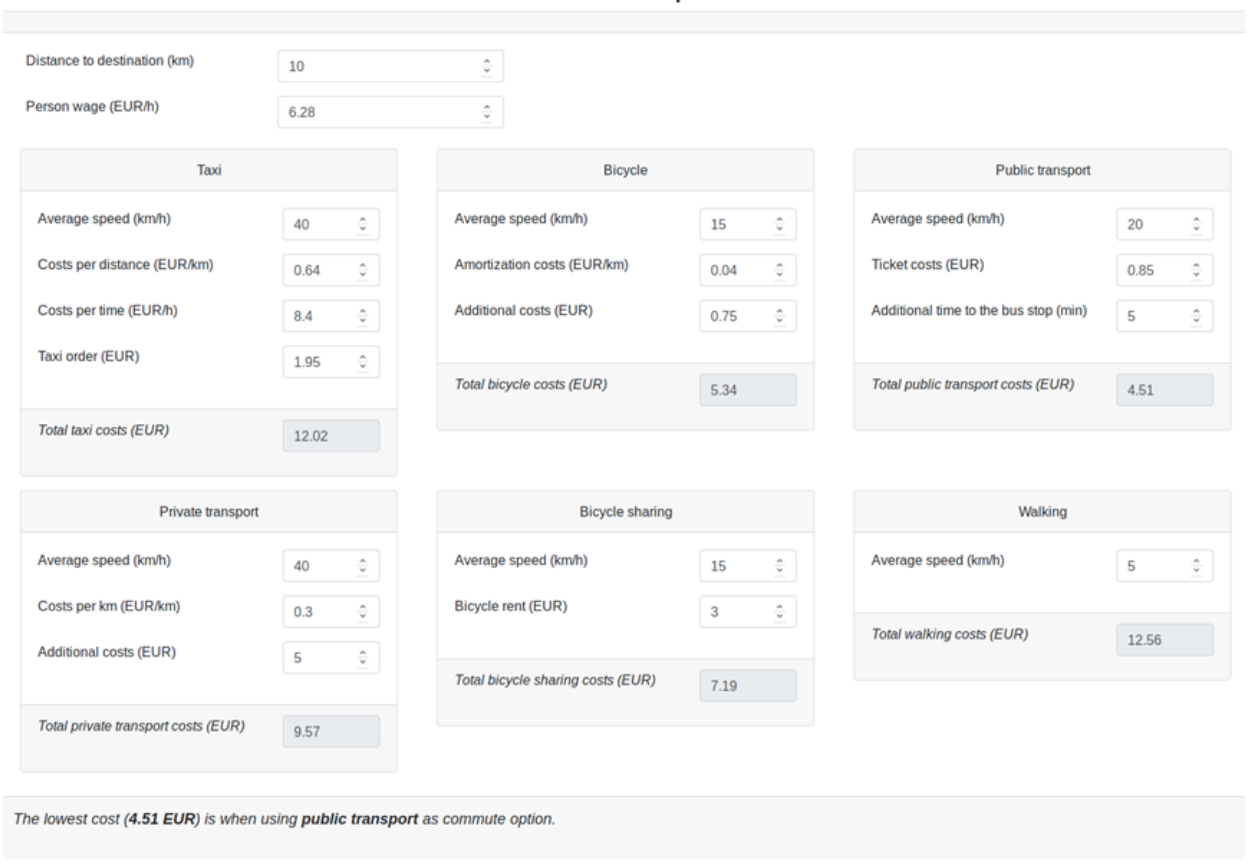

Fig. 6. Transport choice calculation web application

\section{Conclusions}

Proposed models compare costs for using of a different transportation means within the city. Use case is shown for authors' local city Jelgava with local conditions and constraints. Model takes into account person's wage as a basis for calculations, with the reason being that some companies in some countries start thinking of subsidizing the employees for the time they are travelling to the work.

Models show that for authors use case there are no significant difference which transport to choose. However, a car becomes more preferable in case of increasing the person wage, as it allows to reach the destination faster (in given situation). But taking into account additional limitations or additional costs for using a car, i.e., paid parking and paid entrance to the city, it can significantly increase the overall costs for using a car.

Developed web tools allows to easily change parameters and use a model for calculation of costs for different situation and different cities and countries.

Proposed model did not take into account comfort evaluation, i.e., depending on weather conditions choice for a bike can be different. As well infrastructure for a bike could not be ready in some cases. 
It is concluded that taking person's wage into account makes car use more economically reasonable.

In case municipalities limit the use of private cars, additional limitation and costs should be implemented to increase the costs of car use; moreover, use of greener transportation means or a public transport should be promoted.

\section{Acknowledgments}

Scientific research, publication and presentation are supported by the ERANet-LAC Project "Enabling resilient urban transportation systems in smart cities (RETRACT, ELAC2015/T10-0761)".

\section{References}

Anthopoulos, L.G., Reddick, C.G. (2016). Understanding Electronic Government Research and Smart City: A Framework and Empirical Evidence. Information Polity 21(1): 99-117.

Becker, U.J., Becker, T., Gerlach, J. (2012). The True Costs of Automobility: External Costs of Cars. Overview on Existing Estimates in EU-27. 49: 1-52.

Benevolo, C., Dameri, R.P., D’Auria, B. (2013). Smart Mobility in Smart City. In: Empowering Organizations, 13-28.

Cerutti, P.S., Martins, R.D., Macke, J., Rubim Sarate, J. (2019). Green, but Not as Green as That: An Analysis of a Brazilian Bike-Sharing System. Journal of Cleaner Production 217(2-3): 185-193

Chourabi, H., Nam, T., Walker, S., Gil-Garcia, J.R., Mellouli, S., Nahon, K., Pardo, T.A., Scholl, H.J. (2012). Understanding smart cities: An integrative framework. In 2012 45th Hawaii international conference on system sciences (pp. 2289-2297). IEEE.

de Dios Ortuzar, J., Iacobelli, A., Valeze, C. (2000). Estimating demand for a cycle-way network. Transportation Research Part A: Policy and Practice, 34(5), pp.353-373.

Degele, J., Gorr, A., Haas, K., Kormann, D., Krauss, S., Lipinski, P., Tenbih, M., Koppenhoefer, C., Fauser, J., Hertweck, D. (2018). Identifying E-scooter sharing customer segments using clustering. In 2018 IEEE International Conference on Engineering, Technology and Innovation (ICE/ITMC) (pp. 1-8). IEEE.

Elsom, D. (2014). Smog alert: managing urban air quality. Routledge.

Fishman, E., Washington, S., Haworth, N. (2013). Bike share: a synthesis of the literature. Transport reviews, 33(2), pp.148-165.

Goodwill, R. (2015). Transport Minister Encourages People to Get on Their Bike for Cycle to Work Day.

Gössling, S., Choi, A.S. (2015). Transport transitions in Copenhagen: Comparing the cost of cars and bicycles. Ecological Economics, 113, pp.106-113.

Hopkinson, P., Wardman, M. (1996). Evaluating the demand for new cycle facilities. Transport Policy, 3(4), pp.241-249.

Kaltenbrunner, A., Meza, R., Grivolla, J., Codina, J., Banchs, R. (2010). Urban cycles and mobility patterns: Exploring and predicting trends in a bicycle-based public transport system. Pervasive and Mobile Computing, 6(4), pp.455-466.

Kitthamkesorn, S., Chen, A. (2017). Alternate weibit-based model for assessing green transport systems with combined mode and route travel choices. Transportation Research Part B: Methodological, 103, pp.291-310. 
Krizec, K.J. (2007). Estimating the economic benefits of bicycling and bicycle facilities: An interpretive review and proposed methods. In Essays on transport economics (pp. 219-248). Physica-Verlag HD.

Lu, M., Hsu, S.C., Chen, P.C., Lee, W.Y. (2018). Improving the sustainability of integrated transportation system with bike-sharing: A spatial agent-based approach. Sustainable cities and society, 41, pp.44-51.

Mahizhnan, A., 1999. Smart cities: the Singapore case. Cities, 16(1), pp.13-18.

Marceau, J. (2008). Introduction: Innovation in the City and Innovative Cities. Innovation: Management, Policy \& Practice. Innovation 49(2-3): 136-45.

Mayhew, L.J., Bergin, C. (2019). Impact of e- scooter injuries on Emergency Department imaging. Journal of medical imaging and radiation oncology.

Meschik, M. (2012). Reshaping city traffic towards sustainability Why transport policy should favor the bicycle instead of car traffic. Procedia-social and behavioral sciences, 48, pp.495504.

Mi, Z. (2019). The sharing economy promotes sustainable societies. Nature communications, $10(1)$, p. 1214

Mueller, N., Rojas-Rueda, D., Salmon, M., Martinez, D., Ambros, A., Brand, C., De Nazelle, A., Dons, E., Gaupp-Berghausen, M., Gerike, R., Götschi, T. (2018). Health impact assessment of cycling network expansions in European cities. Preventive medicine, 109, pp.62-70.

Woodcock, J., Tainio, M., Cheshire, J., O’Brien, O., Goodman, A. (2014). Health effects of the London bicycle sharing system: health impact modelling study. Bmj, 348, p.g425.

Zacepins, A., Komasilovs, V., Kviesis, A., Gatins, A., Skudra, M., Pierhurovics, A. (2017). Implementation of Smart Parking System in Jelgava City in Latvia. In 2017 IEEE 11th International Conference on Application of Information and Communication Technologies (AICT) (pp. 1-4). IEEE.

Received May 20, 2019, revised August 19, 2019, accepted September 2, 2019 